\title{
Predictors of radiation pneumonitis and pulmonary function changes after concurrent chemoradiotherapy of non-small cell lung cancer
}

\author{
Young Hee Park, MD, Jae-Sung Kim MD \\ Department of Radiation Oncology, Seoul National University Bundang Hospital, \\ Seoul National University College of Medicine, Seoul, Korea
}

\begin{abstract}
Purpose: To evaluate the predictive factors of radiation pneumonitis (RP) and associated changes in pulmonary function after definitive concurrent chemoradiotherapy (CCRT) in patients with non-small cell lung cancer (NSCLC).

Materials and Methods: Medical records of 60 patients with NSCLC who received definitive CCRT were retrospectively reviewed. Dose volumetric (DV) parameters, clinical factors, and pulmonary function test (PFT) data were analyzed. RP was graded according to the CTCAE ver. 4.0. Percentage of lung volume that received a dose of threshold (Vdose) and mean lung dose (MLD) were analyzed for potential DV predictors. PFT changes were calculated as the difference between pre-RT and post-RT values at 3,6 , and 12 months after RT.

Results: Twenty-two patients (37\%) developed grade $\geq 2$ RP. Among clinical factors, tumor location in lower lobe was associated with RP. Among the DV parameters, only MLD $>15$ Gy was associated with grade $\geq 2$ RP. There were statistically significant decreases in PFT at all points compared with pre-RT values in grade $\geq 2$ RP group. MLD was associated with forced vital capacity (FVC) and forced expiratory volume in 1 second (FEV1) changes at 6 and 12 months. V10 was associated with FVC changes at 12 months. $\mathrm{V} 20$ and $\mathrm{V} 30$ were associated with FEV1 changes at 6 months and FVC changes at 12 months.

Conclusion: After definitive CCRT in patients with NSCLC, MLD >15 Gy and lower lobe tumor location were predictors of grade $\geq 2$ RP. Pulmonary functions were decreased after CCRT and the magnitude of changes was associated with DV parameters.
\end{abstract}

Keywords: Non-small-cell lung carcinoma, Radiation pneumonitis, Dose volumetric parameter, Respiratory function test

\section{Introduction}

Radiotherapy is the major treatment modality for patients with locally advanced non-small cell lung cancer (NSCLC). Earlier studies showed superior outcome of concurrent chemoradiotherapy over sequential treatment $[1,2]$. In patients with unresectable tumors or medically inoperable conditions, definitive concurrent chemoradiotherapy (CCRT) has become a standard treatment.
Radiation pneumonitis (RP) is one of the major dose-limiting toxicities in patients receiving radiotherapy for lung cancer. Higher radiation doses will improve local control rate but also increase the incidence of treatment related toxicity [3] Although most patients with mild RP recover spontaneously, some with severe RP suffer from bothering symptoms that can lead to poor quality of life and in a few cases to death. The previously reported incidence of clinically significant RP ranges from roughly $10 \%$ to $40 \%$ of patients receiving definitive

Received 28 October 2012, Revised 18 January 2013, Accepted 12 March 2013.

Correspondence: Jae-Sung Kim, MD, Department of Radiation Oncology, Seoul National University Bundang Hospital, 82 Gumi-ro 173 beon-gil, Bundang-gu, Seongnam 463-707, Korea. Tel: +82-31-787-7652, Fax: +82-31-787-4019, E-mail: jskim@snubh.org

(c) This is an Open Access article distributed under the terms of the Creative Commons Attribution Non-Commercial License (http://creativecommons.org/ licenses/by-nc/3.0/) which permits unrestricted non-commercial use, distribution, and reproduction in any medium, provided the original work is properly cited.

www.e-roj.org 
radiotherapy for lung cancer [4-8]. Clinical manifestations of $\mathrm{RP}$ are usually nonproductive cough, mild fever and dyspnea on exertion. Besides these non-specific symptoms, several other factors such as difference in radiation techniques and variable reporting methods can contribute to the variability of the RP incidence.

Numerous clinical factors such as age, sex, performance status, tumor location, smoking history, underlying lung disease and use of chemotherapy have been evaluated and found to be associated with RP. With the development of three-dimensional (3D) treatment systems, information about the radiation dose distribution of the organ of interest has become available. Many studies evaluated the association between dose volumetric (DV) parameters and risk of RP.

This study is aimed to evaluate the clinical and DV parameters to find out the predictive factors of RP and associated pulmonary function changes in patients with NSCLC who were treated with the definitive CCRT.

\section{Materials and Methods}

\section{Patients}

Between November 2003 and April 2010, seventy patients with NSCLC received definitive CCRT at our institution. Of these patients, 5 patients who were treated for symptom palliation and 4 patients who received incomplete radiotherapy were excluded. One patient who received palliative surgical resection after RT was excluded to eliminate the compounding effect of the surgery on the pulmonary function changes. The remaining 60 patients were retrospectively analyzed in this study.

Patients and tumor characteristics are shown in Table 1. Median age was 65 years (range, 43 to 84 years) and 52 patients were male. Fifty-two patients were current or former smokers. Half of the patients had underlying lung disease, and the most common was chronic obstructive pulmonary disease (COPD). All patients had histologically confirmed NSCLC with the histologic diagnosis of squamous cell carcinoma most common and most patients were in stage III (93.4\%). Forty patients had tumors in upper lobes including middle lobe in case of right lung cancer. A tumor involving the hilum or mediastinum was defined as a central tumor in this study and 39 patients had central tumors.

\section{Treatment}

All patients were treated with curative intent, and none of the patients underwent surgical resection before and after radiotherapy. Twenty-six patients received induction chemotherapy before CCRT. Fifty-eight patients received weekly chemotherapy and the median number of chemotherapy cycle was 6 (range, 2 to 7). Of these patients, fifty patients received paclitaxel $\left(50 \mathrm{mg} / \mathrm{m}^{2}\right)$ and cisplatin $(25$ $\left.\mathrm{mg} / \mathrm{m}^{2}\right)$ and four docetaxel $\left(20 \mathrm{mg} / \mathrm{m}^{2}\right)$ and cisplatin $\left(20 \mathrm{mg} / \mathrm{m}^{2}\right)$ as a concurrent chemotherapy regimen. Radiotherapy was delivered using conventional fractionation (1.8-2.0 Gy per day, 5 days per week) with median total dose 66 Gy (range, 59.4 to $70 \mathrm{~Gy}$ ). Fifty-five patients receive 3D conformal radiotherapy

Table 1. Patient characteristics

\begin{tabular}{|c|c|}
\hline Characteristics & No. of patients $(\%)$ \\
\hline Age (yr), median (range) & $64.6(43-84)$ \\
\hline \multicolumn{2}{|l|}{ Sex } \\
\hline Male & $52(85.2)$ \\
\hline Female & $8(14.8)$ \\
\hline \multicolumn{2}{|l|}{ ECOG performance } \\
\hline 0 & $12(19.7)$ \\
\hline 1 & $42(70.5)$ \\
\hline 2 & $6(9.8)$ \\
\hline \multicolumn{2}{|l|}{ Smoking history } \\
\hline Yes & $52(86.9)$ \\
\hline No & $8(13.1)$ \\
\hline \multicolumn{2}{|l|}{ Underlying lung disease } \\
\hline Yes & $33(54.1)$ \\
\hline COPD & 22 \\
\hline Tuberculosis & 8 \\
\hline Interstitial lung disease & 3 \\
\hline Asthma & 6 \\
\hline No & $27(45.9)$ \\
\hline \multicolumn{2}{|l|}{ Neoadjuvant chemotherapy } \\
\hline Yes & $26(42.6)$ \\
\hline No & $34(57.4)$ \\
\hline \multicolumn{2}{|l|}{ Histology } \\
\hline Adenocarcinoma & $14(24.6)$ \\
\hline Squamous cell carcinoma & $37(60.7)$ \\
\hline Others \& not specified & $9(14.7)$ \\
\hline \multicolumn{2}{|l|}{ Stage } \\
\hline IA & $1(1.6)$ \\
\hline$\| B$ & $3(4.9)$ \\
\hline$\| \mathrm{A}$ & $23(39.3)$ \\
\hline IIIB & $33(54.1)$ \\
\hline \multicolumn{2}{|l|}{ Tumor location } \\
\hline Upper (including middle in Rt. Lung) & $40(67.2)$ \\
\hline Lower & $20(32.8)$ \\
\hline Central & $39(63.9)$ \\
\hline Peripheral & $21(36.1)$ \\
\hline
\end{tabular}

ECOG, the Eastern Cooperative Oncology Group; COPD, chronic obstructive pulmonary disease. 
but 5 patients received initial conventional 2D radiotherapy followed by 3D conformal boost and these patients were not evaluated in the analysis of dose volumetric (DV) parameters. DV parameters included in the analysis were mean lung dose (MLD), percentage of lung volume receiving a dose of $10 \mathrm{~Gy}$ or more (V10), 20 Gy of more (V20), 30 Gy or more (V30).

\section{Pulmonary function tests}

Pulmonary function tests (PFT) were obtained before RT and 3, 6 , and 12 months after completion of RT. Forced vital capacity (FVC), forced expiratory volume in 1 second (FEV1) and diffusion capacity for carbon monoxide (DLCO) were expressed as a percentage of the normal value (based on age, weight, and gender). Changes of PFT were calculated as the difference between the pre- and post-RT PFT values relative to the pre-RT values [9].

\section{Radiation pneumonitis}

RP was evaluated retrospectively by reviewing the medical records and follow-up imaging of the patients. All clinical symptoms and radiographic changes were considered. RP was graded according to the Common Terminology Criteria for Adverse Events (CTCAE) ver. 4.0.

Table 2. Analysis of clinical and dose volumetric parameters for association with grade $\geq 2$ radiation pneumonitis

\begin{tabular}{|c|c|c|c|c|}
\hline \multirow{2}{*}{ Variables } & \multicolumn{2}{|c|}{ No. of patients } & \multicolumn{2}{|c|}{$p$-value ${ }^{b)}$} \\
\hline & Grade $<2$ RP & Grade $\geq 2 \mathrm{RP}$ & Univariate & Multivariate \\
\hline Age (yr) & & & NS & NS \\
\hline$\leq 65$ & 19 & 13 & & \\
\hline$>65$ & 19 & 9 & & \\
\hline Gender & & & NS & NS \\
\hline Male & 35 & 17 & & \\
\hline Female & 3 & 5 & & \\
\hline Smoking history & & & NS & NS \\
\hline Yes & 34 & 18 & & \\
\hline No & 4 & 4 & & \\
\hline Underlying lung disease & & & NS & NS \\
\hline Yes & 16 & 12 & & \\
\hline No & 22 & 10 & & \\
\hline Neoadjuvant chemotherapy & & & NS & NS \\
\hline Yes & 16 & 10 & & \\
\hline No & 22 & 12 & & \\
\hline \multicolumn{5}{|l|}{ Tumor location } \\
\hline Upper & 30 & 10 & 0.011 & - \\
\hline Lower & 8 & 12 & & \\
\hline Central & 27 & 12 & NS & NS \\
\hline Peripheral & 11 & 10 & & \\
\hline Mean lung dose (Gy) & & & 0.027 & 0.025 \\
\hline$\leq 15$ & 20 & 5 & & \\
\hline$>15$ & 15 & 15 & & \\
\hline $\mathrm{V} 10^{\mathrm{a})}(\%)$ & & & NS & NS \\
\hline$\leq 55$ & 31 & 17 & & \\
\hline$>55$ & 4 & 3 & & \\
\hline $\mathrm{V} 20^{\mathrm{a})}(\%)$ & & & NS & NS \\
\hline$\leq 30$ & 23 & 9 & & \\
\hline$>30$ & 12 & 11 & & \\
\hline V30 $(\%)$ & & & 0.084 & NS \\
\hline$\leq 20$ & 26 & 10 & & \\
\hline$>20$ & 9 & 10 & & \\
\hline
\end{tabular}

$R P$, radiation pneumonitis; NS, not significant.

${ }^{a}$ Vdose, percentage of lung volume receiving more than a threshold dose. ${ }^{b}$ p-values from Fischer's exact test. 


\section{Statistical analysis}

To evaluate the effect of the DV parameters on development of RP, Fisher's exact test was used. Using paired t-test, we compared the PFT parameters at 3, 6, and 12 months after completion of radiotherapy with the pre-RT values, and using independent t-test, the association between RP and PFT changes was investigated. The association between DV parameters and PFT changes were tested by correlation analysis. All statistical analysis was performed using SPSS ver. 18 (SPSS Inc., Chicago, IL, USA).

\section{Results}

\section{Prognostic factors for grade $\geq 2$ radiation pneumonitis}

Follow-up duration for patients ranged 3 to 88 months (median, 21 months). No patient developed grade $\geq 3$ RP. Twelve patients (20.0\%) did not develop RP, 26 (43.3\%) developed grade 1 RP, and 22 (36.7\%) grade 2 RP. The mean
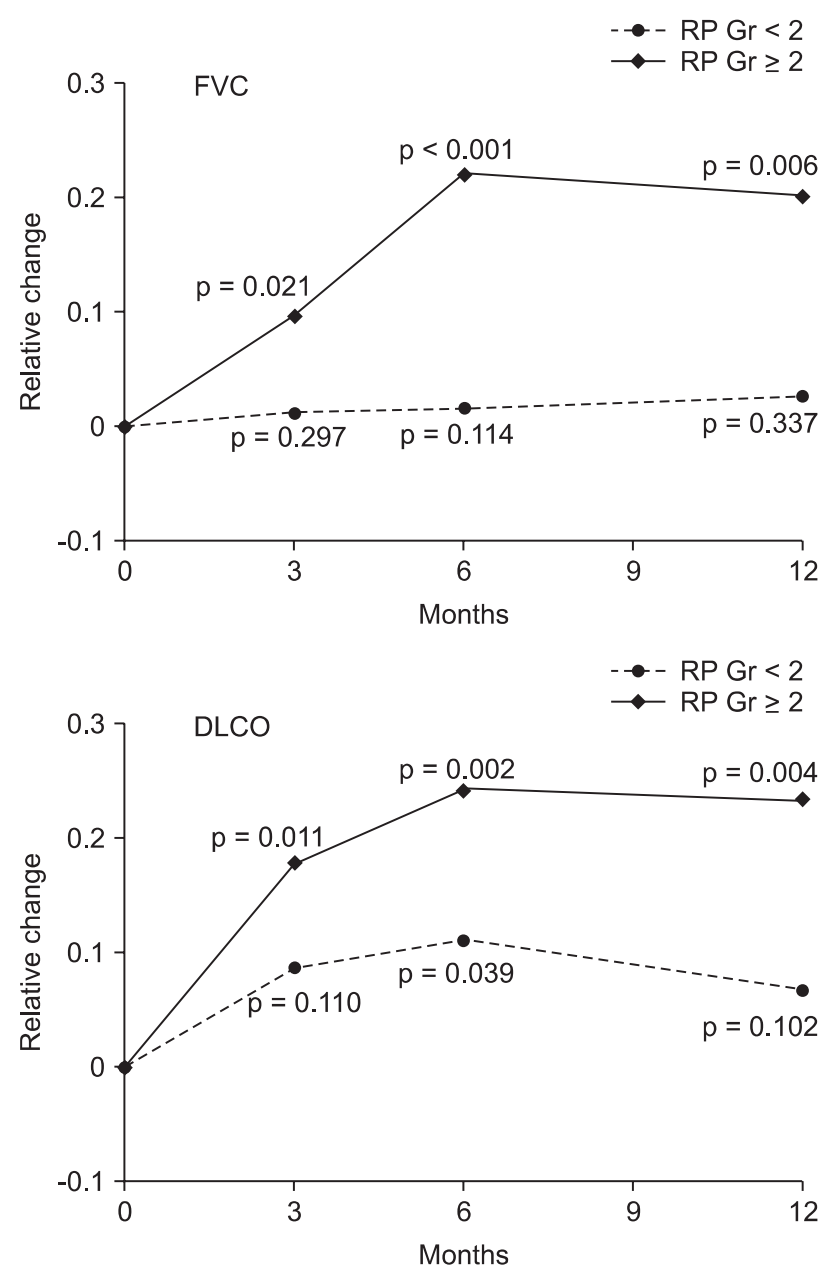

values of MLD, V10, V20, and V30 were $13.2 \mathrm{~Gy}, 42.4 \%, 25.9 \%$, and $16.5 \%$ in the group with grade $<2 \mathrm{RP}$, and $15.6 \mathrm{~Gy}, 46.2 \%$, $29.7 \%$, and $20.0 \%$ in the grade $\geq 2$ RP group. Among these parameters, only the mean MLD was significantly different between two groups.

The results of univariate and multivariate analysis to find the prognostic factors for grade $\geq 2 \mathrm{RP}$ are summarized in Table 2. In univariate analysis for development of grade $\geq 2 \mathrm{RP}$, lower lobe tumor and MLD >15 Gy were significant prognostic factors but in multivariate analysis, only MLD was significantly associated with the development of grade $\geq 2 \operatorname{RP}(p=0.025)$. Because lower lobe tumor was closely associated with MLD $>15 \mathrm{~Gy}$, tumor location was excluded in the multivariate analysis to remove the multicollinearity.

\section{Pulmonary function changes and radiation pneumonitis} PFT parameters at 3,6, and 12 months after completion of RT were compared with pre-RT value and the mean relative

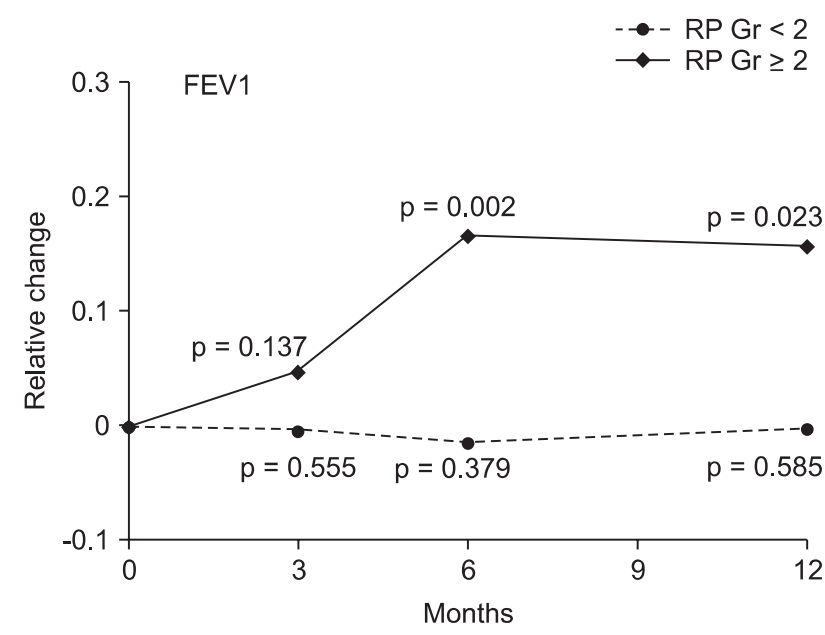

Fig. 1. The changes of pulmonary functions (FVC, FEV1, and DLCO) after CCRT. The relative changes of pulmonary function were difference between the pre- and post-RT PFT values relative to the pre-RT values. $p$-values are from paired t-test. RP, radiation pneumonitis; FVC, forced vital capacity; FEV1, forced expiratory volume in 1 second; DLCO, diffusion capacity for carbon monoxide; CCRT, concurrent chemoradiotherapy; RT, radiotherapy; PFT, pulmonary function tests. 
changes of 3 PFT parameters (FVC, FEV1, and DLCO) were compared between the group with grade $\geq 2 \mathrm{RP}$ and with grade $<2$ RP. The mean values of PFT change were significantly higher in the group with grade $\geq 2$ RP at 6 and 12 months.

The relative changes of $\mathrm{FVC}, \mathrm{FEV} 1$, and DLCO are illustrated in the Fig. 1. The mean relative reduction of $\mathrm{FVC}, F E V 1$, and DLCO in patients with grade $\geq 2$ were $9.7 \%, 15.7 \%$, and $23.3 \%$ at 3 months, 4.6\%, 17.9\%, and $22.1 \%$ at 6 months, $16.7 \%, 24.2 \%$, and $20.1 \%$ at 12 months after RT, respectively. In the group with grade $\geq 2 \mathrm{RP}$, all PFT parameters significantly decreased after RT, except FEV1 change at 3 months. In contrast, there were no significant changes of PFT in the grade $<2$ RP group, except DLCO change at 6 months.

\section{Dose Volumetric parameters and pulmonary function changes}

MLD was associated with the change of FVC and FEV 1 at 6 and 12 months after RT (Table 3). V10 was associated with FVC change at 12 months and V20 and V30 were associated with FEV 1 change at 6 months and FVC changes at 12 months.

\section{Discussion and Conclusion}

Radiation pneumonitis is the most common toxicity after radiotherapy for thoracic tumors and can have substantial influence on the morbidity and mortality of patients with lung cancer. Therefore, it is essential to find out the predictive factors for the development of RP to reduce the incidence of RP. Many studies reported that radiation dose and irradiated lung volumes are closely associated with the risk of RP. Several DV parameters have been proposed as predictive factors for
RP but still there is no consensus about which parameters are ideal for predicting the RP.

Many studies reported several clinical factors as predictive factors for development of RP [10-12]. Factors such as age, gender, pretreatment performance status, smoking history, underlying lung disease and tumor location have been proposed as predictive factors. But in this study, all clinical factors except tumor location did not show any correlation with the development of RP. One possible explanation for this result is the small sample size in this study, but we suppose the discreet use of individualized radiotherapy as another factor. If a patient is old, has chronic lung disease and therefore has poor pre-RT lung function, we tried to modify the treatment plan and restrict the DV parameters more strictly and consequently the DV parameters of the patient showed lower DV parameters than conventionally planned cases. This consideration might have compensated for the RP susceptibility of these vulnerable patients.

Many studies have suggested various DV parameters as predictive factors for RP but no consensus about the ideal parameter has been reached $[6,7,13-16]$. The various results are difficult to compare directly because of several reasons. First, the definition of RP and the toxicity grading systems are different among the studies. Second, the population of the patients investigated is heterogeneous. Third, the treatment technique, dose and fractionation schemes are varied. In this study, we included the patients who were treated with the radical CCRT to improve the homogeneity of the study population, and all the patients received relatively consistent radiation dose and fractionation scheme.

There was no grade $\geq 3 \mathrm{RP}$ in this study with following

Table 3. Association between DV parameters and PFT changes

\begin{tabular}{|c|c|c|c|c|c|}
\hline & & MLD & V10 & $\mathrm{V} 20^{\mathrm{a})}$ & $\mathrm{V} 30^{\mathrm{a})}$ \\
\hline \multirow[t]{3}{*}{3 mo after RT } & $\mathrm{FVC}(\mathrm{n}=43)$ & NS & NS & NS & NS \\
\hline & FEV1 $(n=43)$ & NS & NS & NS & NS \\
\hline & $\operatorname{DLCO}(n=26)$ & NS & NS & NS & NS \\
\hline \multirow[t]{3}{*}{6 mo after RT } & FVC $(n=38)$ & $0.007^{b)}$ & NS & NS & NS \\
\hline & FEV1 $(n=38)$ & $0.001^{b)}$ & NS & $0.020^{b)}$ & $0.014^{b)}$ \\
\hline & $\operatorname{DLCO}(n=22)$ & NS & NS & NS & NS \\
\hline \multirow[t]{3}{*}{12 mo after RT } & FVC $(n=28)$ & $0.007^{b)}$ & $0.039^{b)}$ & $0.011^{b)}$ & $0.045^{b)}$ \\
\hline & FEV1 $(n=28)$ & $0.045^{b)}$ & NS & NS & NS \\
\hline & $\operatorname{DLCO}(n=19)$ & NS & NS & NS & NS \\
\hline
\end{tabular}

DV, dose volumetric; PFT, pulmonary function tests; RT, radiotherapy; FVC, forced vital capacity; FEV1, forced expiratory volume in 1 second; DLCO, diffusion capacity for carbon monoxide; NS, not significant.

${ }^{a}$ Vdose, percentage of lung volume receiving more than a threshold dose. ${ }^{b)} p$-values from correlation analysis. 
possible reasons. In this study, all patients were treated with definitive CCRT and therefore the general condition of patients might be relatively better than in other studies. It might represent that the patients had the potential to tolerate the treatments and complications as well. As mentioned before, if the patient has the clinical factors predisposing to RP, we tried to modify the treatment plan to achieve favorable DV parameters as possible. This could reduce the final lung complications of the patients with poor clinical factors.

In this study, V10, V20, and V30 were not associated with the grade $\geq 2$ RP but the MLD was significant predictive factor for grade $\geq 2$ RP. This is comparable to the previous studies [17-19]. Wang et al. [19] reported the association between the MLD and grade $\geq 3$ RP. They investigated 223 patients treated with definitive CCRT and the severity of pneumonitis was graded according to the CTCAE v3.0. In univariate analysis, the MLD and V5 through V65 were associated with the RP. Patients with MLD >16.5 Gy had a higher incidence of grade $\geq 3$ RP (13\% vs. 36\%). In the study of Kim et al. [18], MLD showed the significant association with severe RP in multivariate analysis. They analyzed 76 patients who were treated with 3D conformal radiotherapy with curative intent. They scored the severity of RP with the Radiation Therapy Oncology Group criteria and severe RP was defined as grade $\geq 3$ RP. V20, V30, V40, and V50, normal tissue complication probability and MLD were associated with severe RP in univariate analysis. But in multivariate analysis, MLD $\geq 15$ Gy was the only significant predictive factor for grade $\geq 3 \mathrm{RP}$.

Regarding to pulmonary function changes after CCRT, there were significant reductions in pulmonary function after radiotherapy and the change was prominent in grade $\geq 2 \mathrm{RP}$. Many investigators showed the decline in the PFT, and its correlation with the symptoms. Borst et al. [9] reported the change of pulmonary function in patients with long term disease free survival. At 3 months after RT, decline in the PFT were observed and that was not recovered thereafter. The change of pulmonary function was associated with the MLD. Miller et al. [20] reported similar result that showed significant reduction in PFT at 6 months after RT which continued beyond 1 year. Our study demonstrated similar results that PFT declined until 6 months and then stabilized by 1 year after radiotherapy. In addition, we separately evaluated the PFT changes according to the grade of RP. As expected, the PFT reduction was more prominent in the patients with grade $\geq 2$ RP than the other patients. Grade of RP is relatively subjective because it depends on the patient's symptoms and the physician's assessment. But with PFT changes in this study, severity of RP could be expressed in the magnitude of PFT changes in more objective way.

Reduction in some PFT parameters was associated with the DV parameters. Because this study is basically retrospective and not all PFT parameters (FVC, FEV1, and DLCO) were checked regularly at every time, no consistent relationship was shown between PFT and DV parameters. But in spite of these limitations, we can assume the association with some DV parameters and PFT changes. Among the DV parameters, MLD was associated FVC and FEV1 at 6 and 12 months. Also it can be speculated that the DV parameters were significantly associated with the grade $\geq 2 \mathrm{RP}$ and the PFT change was more prominent in the grade $\geq 2$ RP. From these results, we expect the clinical guidance about the radiation pneumonitis, DV parameters, and PFT changes which need to be explored with forthcoming studies.

The development of grade $\geq 2$ RP after definitive CCRT in NSCLC is significantly associated with the MLD >15 Gy. There was considerable reduction in pulmonary function after radiotherapy and the relative reduction is higher in the group who developed grade $\geq 2 \mathrm{RP}$. The mean relative reduction of FVC, FEV1, DLCO in patients with grade $\geq 2$ were $9.7 \%, 15.7 \%$, and $23.3 \%$ at 3 months, $4.6 \%, 17.9 \%$, and $22.1 \%$ at 6 months, $16.7 \%, 24.2 \%$, and $20.1 \%$ at 12 months after RT, respectively. The magnitude of pulmonary function change was also closely associated with the radiotherapy DV parameters.

\section{Conflict of Interest}

No potential conflict of interest relevant to this article was reported.

\section{References}

1. Furuse $K$, Fukuoka $M$, Kawahara $M$, et al. Phase III study of concurrent versus sequential thoracic radiotherapy in combination with mitomycin, vindesine, and cisplatin in unresectable stage III non-small-cell lung cancer. J Clin Oncol 1999;17:2692-9.

2. Curran WJ Jr, Paulus R, Langer CJ, et al. Sequential vs. concurrent chemoradiation for stage III non-small cell lung cancer: randomized phase III trial RTOG 9410. J Natl Cancer Inst 2011;103:1452-60.

3. Perez CA, Stanley K, Grundy G, et al. Impact of irradiation technique and tumor extent in tumor control and survival of patients with unresectable non-oat cell carcinoma of the 
lung: report by the Radiation Therapy Oncology Group. Cancer 1982;50:1091-9.

4. Yorke ED, Jackson A, Rosenzweig KE, et al. Dose-volume factors contributing to the incidence of radiation pneumonitis in non-small-cell lung cancer patients treated with threedimensional conformal radiation therapy. Int J Radiat Oncol Biol Phys 2002;54:329-39.

5. Kwa SL, Theuws JC, Wagenaar A, et al. Evaluation of two dosevolume histogram reduction models for the prediction of radiation pneumonitis. Radiother Oncol 1998;48:61-9.

6. Graham MV, Purdy JA, Emami B, et al. Clinical dose-volume histogram analysis for pneumonitis after 3D treatment for non-small cell lung cancer (NSCLC). Int J Radiat Oncol Biol Phys 1999:45:323-9.

7. Tsujino $K_{1}$ Hirota $S$, Endo $M$, et al. Predictive value of dosevolume histogram parameters for predicting radiation pneumonitis after concurrent chemoradiation for lung cancer. Int J Radiat Oncol Biol Phys 2003;55:110-5.

8. Rancati T, Ceresoli GL, Gagliardi G, Schipani S, Cattaneo GM. Factors predicting radiation pneumonitis in lung cancer patients: a retrospective study. Radiother Oncol 2003;67:27583.

9. Borst GR, De Jaeger K, Belderbos JS, Burgers SA, Lebesque JV. Pulmonary function changes after radiotherapy in non-smallcell lung cancer patients with long-term disease-free survival. Int J Radiat Oncol Biol Phys 2005;62:639-44.

10. Claude $L$, Perol $D$, Ginestet $C$, et al. A prospective study on radiation pneumonitis following conformal radiation therapy in non-small-cell lung cancer: clinical and dosimetric factors analysis. Radiother Oncol 2004;71:175-81.

11. Shi A, Zhu G, Wu H, Yu R, Li F, Xu B. Analysis of clinical and dosimetric factors associated with severe acute radiation pneumonitis in patients with locally advanced non-small cell lung cancer treated with concurrent chemotherapy and intensity-modulated radiotherapy. Radiat Oncol 2010;5:35.
12. Robnett TJ, Machtay M, Vines EF, McKenna MG, Algazy KM, McKenna WG. Factors predicting severe radiation pneumonitis in patients receiving definitive chemoradiation for lung cancer. Int J Radiat Oncol Biol Phys 2000;48:89-94.

13. Dang J, Li G, Lu X, Yao L, Zhang S, Yu Z. Analysis of related factors associated with radiation pneumonitis in patients with locally advanced non-small-cell lung cancer treated with three-dimensional conformal radiotherapy. J Cancer Res Clin Oncol 2010;136:1169-78.

14. Mehta $V$. Radiation pneumonitis and pulmonary fibrosis in non-small-cell lung cancer: pulmonary function, prediction, and prevention. Int J Radiat Oncol Biol Phys 2005;63:5-24.

15. Yamada M, Kudoh S, Hirata K, Nakajima T, Yoshikawa J. Risk factors of pneumonitis following chemoradiotherapy for lung cancer. Eur J Cancer 1998;34:71-5.

16. Rodrigues G, Lock M, D'Souza D, Yu E, Van Dyk J. Prediction of radiation pneumonitis by dose - volume histogram parameters in lung cancer: a systematic review. Radiother Oncol 2004;71:127-38.

17. Kwa SL, Lebesque JV, Theuws JC, et al. Radiation pneumonitis as a function of mean lung dose: an analysis of pooled data of 540 patients. Int J Radiat Oncol Biol Phys 1998;42:1-9.

18. Kim TH, Cho KH, Pyo HR, et al. Dose-volumetric parameters for predicting severe radiation pneumonitis after threedimensional conformal radiation therapy for lung cancer. Radiology 2005;235:208-15.

19. Wang $S$, Liao Z, Wei $X$, et al. Analysis of clinical and dosimetric factors associated with treatment-related pneumonitis (TRP) in patients with non-small-cell lung cancer (NSCLC) treated with concurrent chemotherapy and three-dimensional conformal radiotherapy (3D-CRT). Int J Radiat Oncol Biol Phys 2006;66:1399-407.

20. Miller KL, Zhou SM, Barrier RC Jr, et al. Long-term changes in pulmonary function tests after definitive radiotherapy for lung cancer. Int J Radiat Oncol Biol Phys 2003;56:611-5. 